\title{
ESCRITAS DE SI, ESCRITAS DA LIBERDADE: REPRESENTAÇÕES SOBRE AS VIAGENS EM AUTOBIOGRAFIAS DE ESCRAVIZADOS ${ }^{1}$
}

\section{ALEXANDRA LIMA DA SILVA}

Universidade do Estado do Rio de Janeiro

RESUMO

\section{ABSTRACT}

Compreender os significados das representações sobre as viagens construídas em autobiografias escritas por sujeitos nascidos na escravidão, nos Estados Unidos, no século XIX, é o horizonte do presente trabalho. Harriet Jacobs, Amanda Berry Smith, Frederick Douglass, Booker Washington e John Brown, nascidos no cativeiro, fizeram uso da palavra e das viagens, para construir a própria liberdade. 0 presente estudo situa-se no campo da história da educação e compreende as narrativas de vida como um ego-documento, uma vez que a narrativa e a memória são elementos constituintes da prática de registrar a própria vida. Viajar e escrever foram caminhos da liberdade, no plural.

Palavras-chave: Autobiografias. Escravizados. Viagens. Histórias da Educação.

\section{SELF-WRITINGS, WRITINGS OF FREEDOM: TRAVEL REPRESENTATIONS IN SLAVE AUTOBIOGRAPHIES}

Understanding the meanings of representations about the journeys built up in autobiographies written by subjects born in slavery in the United States in the nineteenth century is the horizon of this work. Names like Harriet Jacobs, Amanda Berry Smith, Frederick Douglass, Booker Washington and John Brown, born in captivity, took the words and travels to build their own freedom. The present study is in the field of the history of education and understands the narratives of life as an ego-document, since narrative and memory are constituent elements of the practice of recording one's life. Traveling and writing were paths of freedom in the plural.

Keywords: Autobiographies. Slaves. Travels. History of education.

1 Este texto é fruto do projeto de pesquisa "Sujeitos em trânsito: redes de sociabilidade, instituições e circulação de saberes", e conta com a bolsa Jovem Cientista do Nosso Estado, concedida pela FAPERJ. 


\section{RESUMEN ESCRITURAS DE SI, ESCRITURAS DE LA LIBERTAD: REPRESENTACIONES SOBRE LOS VIAJES EN AUTOBIOGRAFÍAS DE ESCLAVIZADOS}

Comprender los significados de las representaciones sobre los viajes en las autobiografías escritas por sujetos nacidos en la esclavitud en los Estados Unidos, en el siglo XIX, es el horizonte del presente trabajo. Nombres como Harriet Jacobs, Amanda Berry Smith, Frederick Douglass, Booker Washington y John Brown, nacidos en cautiverio, hicieron uso de la palabra y de los viajes, para construir la libertad. El presente estudio se sitúa en el campo de la historia de la educación y comprende las narrativas de vida como un ego-documento, ya que la narración y la memoria son elementos constituyentes de la práctica de registrar la propia vida. Viajar y escribir fueron caminos de la libertad, en el plural.

Palabras clave: Autobiografias. Esclavizados. Viajes. Historia de la educación.

\section{Introdução}

Sujeitos em trânsito, ideias em movimento. Momento excepcional na vida das pessoas, a viagem torna-se importante passagem em uma autobiografia. A partir da análise das autobiografias escritas por pessoas nascidas na condição de escravos, nos Estados Unidos, no século XIX, procuro compreender as representações sobre as viagens. Harriet Jacobs, Frederick Douglass, Amanda Berry Smith, Booker Washington, John Brown e Levi Branham, por exemplo, fizeram uso da palavra, em primeira pessoa, para contar a própria vida.-Conhecer outras paisagens foi parte do movimento em busca de emancipação plena. A viagem foi mais um caminho para a construção da liberdade.

O presente estudo situa-se no campo da História da Educação e compreende as narrativas de vida como um ego-documento, uma vez que a narrativa e a memória são elementos constituintes da prática de registrar a própria vida. Viajar e escrever foram caminhos da liberdade, no plural. De acordo com a Encyclo- pedia Britannica, slave narrative "é um relato de vida, ou de grande parte da vida de um fugitivo ou ex-escravo, seja escrito ou oral - feito pelo próprio sujeito". Tais narrativas constituem uma das mais influentes tradições na Literatura norte-americana, estando presentes em escritas controversas - tanto na ficção, quanto na autobiografia - na história dos Estados Unidos. ${ }^{2}$

Escrita em dois volumes, The interesting narrative of the life of Olaudah, ${ }^{3}$ datada de 1789, é vista como uma das primeiras narrativas de escravos a tornar-se um best-seller internacional. Deste modo, "desde 1776, mais de 200 autobiografias de escravos livres foram publicadas nos Estados Unidos e Inglaterra. Milhares de discursos gravados taquigraficamente, depoimentos e entrevistas com escra-

2 "Slave narrative." Encyclopedia Britannica, 2008. Disponivel em: <http://global.britannica.com/EBchecked/topic/548224/slave-narrative>. Acesso em: 19 jun. 2014.

3 Obra disponivel em: <http://docsouth.unc.edu/neh/ equiano1/equiano1.html . Acesso em: 19 jun. 2014. 
vos e ex-escravos foram obtidos por jornalistas, acadêmicos e funcionários do governo" (MILLER; SMITH, 1988, p. 71).

A documentação analisada no presente estudo integra a coleção North American Slave Narratives, parte constituinte do projeto Documenting the American South (DocSouth), da University Library of the University of North Carolina at Chapel Hill. ${ }^{4}$ A coleção North American Slave Narratives foi coordenada pelo professor William L. Andrews, que coeditou o processo de digitalização das autobiografias de escravos e ex-escravos. Inclui grande número de narrativas autobiográficas de escravos fugidos e libertos, publicadas em inglês, até o ano de 1920, em variados suportes, tais como jornais, panfletos ou livros.

Tal documentação já foi explorada em muitos estudos, sobretudo por pesquisadores dos Estados Unidos. Ao recortar o primeiro século de autobiografias de afro-americanos, William L. Andrews problematiza a questão étnica, pela qual os próprios autobiógrafos foram os responsáveis, especialmente, em sua tentativa de construir uma comunidade de sentido e compreensão entre brancos e negros, em um movimento de busca por uma linguagem através da qual o desconhecido, dentro do eu, e o indizível, no âmbito da escravidão, pudessem, ambos, ser expressos em palavras (ANDREWS, 1986a, p. 9).

$\mathrm{Na}$ perspectiva de Olney (1990), é muito dificil classificar as narrativas de ex-escravos, uma vez que é bastante complexo agrupá-las em História, Literatura ou autobiografia. Para este autor, a autobiografia pode ser entendida como um ato de recordação ou narrativa em que o escritor, a partir de certo ponto de sua vida presente, olha os eventos do passado, a fim de relatá-los de forma a mostrar de que maneira esse passado o constitui no presente

4 Para mais informações a respeito do projeto, consultar: <http://docsouth.unc.edu/neh/intro.html>. estado de ser. Assim, a autobiografia não é um gravador neutro e passivo, mas, sim, um dispositivo criativo e ativo (OLNEY, 1990, p. 47). Por sua vez, as narrativas de vida de ex-escravos foram importantes fontes utilizadas pelos historiadores, no processo de revisão da historiografia nos Estados Unidos, tendo em Genovese (1972) um de seus representantes.

Assim, a prática da viagem possui diferentes significados: filosóficos, literários, míticos, científicos, compulsórios, religiosos, missionários, migratórios, turísticos, amorosos etc.

Um dos entendimentos para a ideia de viagem remete a uma prática social repleta de sentidos e significados, que varia de acordo com o período, o lugar social de quem a pratica e suas motivações. Em $O$ pacto autobiográfico, Philip Lejeune (2008) revela que a escrita no diário, como forma de escrita autobiográfica, codificada pela fusão entre autornarrador, diferencia-se de outras formas de narrativas, como a autobiografia, a biografia e a memória. Acentua, ainda, o leitor como fundamental, na consideração de um texto como autobiográfico, atentando para a noção de um pacto que se firma entre quem escreve e quem lê o texto proposto. Por sua vez, as narrativas de viagem, sejam sob a forma de diário, de cartas a um único interlocutor, ou ainda, de relatórios informais ou científicos, muitas vezes não se afastam do imediato da experiência, tornando dificil a análise. 0 cotidiano relatado parece não conter um encadeamento, completa-se no acontecimento narrado; é breve, exterior e desconexo, dando poucas oportunidades de penetração e de estabelecimento de ligações. Além disso, a narrativa de viagem é frequentemente composta de monumentos fixados pelo mundo interior do viajante (LEITE, 1997, p. 30).

Para o sociólogo Octávio lanni, "a história dos povos está atravessada pela viagem, como realidade ou metáfora", uma vez que, nas mais 
diferentes culturas e organizações humanas, há o elemento viagem, "seja como modo de descobrir o 'outro', seja como modo de descobrir o 'eu'"(IANNI, 2000, p. 13). 0 autor tece uma importante reflexão sobre a viagem, enquanto prática repleta de significados, complexificando, devidamente, esta categoria de análise:

Em geral, a viagem compreende vários significados e conotações, simultâneas, complementares ou mesmo contraditórias. São muitas as formas das viagens reais ou imaginárias, demarcando momentos ou épocas mais ou menos notáveis da vida de indivíduos, famílias, grupos, coletividades, povos, tribos, clãs, nações, nacionalidades, culturas e civilizações. São muitos os que buscam o desconhecido, a experiência insuspeitada, a surpresa da novidade, a tensão escondida nas outras formas de ser, sentir, agir, realizar, lutar, pensar ou imaginar. (IANNI, 2000, p. 13)

A ideia de deslocamento também povoa os entendimentos que muitos produzem sobre viagem, associada, por sua vez, às categorias de tempo e espaço, em uma relação íntima e estreita. Para Octávio Ianni (2000), a viagem tem a capacidade de alterar o significado do tempo e do espaço, pois "leva consigo implicações inesperadas e surpreendentes. 0 veIho mundo somente começou a existir quando os navegantes descobriram e conquistaram o novo mundo".

Quais os significados das viagens para os sujeitos nascidos escravos? Quais as representações construídas sobre as viagens, nas autobiografias de pessoas nascidas na escravidão?

Tabela 1 - Autobiografias de sujeitos nascidos na escravidão

\begin{tabular}{|c|c|c|c|}
\hline Autor & Título & $\begin{array}{l}\text { Ano da primeira } \\
\text { edição }\end{array}$ & Viagens \\
\hline Amanda Berry Smith & $\begin{array}{l}\text { An autobiography: } \\
\text { the story of the } \\
\text { Lord's dealings } \\
\text { with Mrs. Amanda } \\
\text { Smith, the colored } \\
\text { evangelist }\end{array}$ & 1893 & $\begin{array}{l}\text { Travels in America, } \\
\text { England, Ireland, } \\
\text { Scotland, India, } \\
\text { and Africa as an } \\
\text { independent missionary }\end{array}$ \\
\hline Harriet Ann Jacobs & $\begin{array}{l}\text { Incidentes na vida de } \\
\text { uma escrava }\end{array}$ & 1861 & Inglaterra \\
\hline John Brown & $\begin{array}{l}\text { Life in Georgia: a } \\
\text { narrative of the } \\
\text { life, sufferings, } \\
\text { and escape of John } \\
\text { Brown, a fugitive } \\
\text { slave, now in England }\end{array}$ & 1855 & Inglaterra \\
\hline Levi Branham & My life and travels & 1929 & $\begin{array}{l}\text { No interior do Estado } \\
\text { da Geórgia e outros } \\
\text { estados no EUA }\end{array}$ \\
\hline Frederick Douglass & $\begin{array}{l}\text { Narrative of life } \\
\text { of the Frederick } \\
\text { Douglass (1845); } \\
\text { My bondage and my } \\
\text { Freedom (1855); } \\
\text { Life and times of } \\
\text { Frederick Douglass } \\
\text { (1881) }\end{array}$ & & $\begin{array}{l}\text { Viagens para dentro dos } \\
\text { Estados Unidos e para } \\
\text { fora: Inglaterra, França, } \\
\text { Itália, Egito, Grécia, } \\
\text { Suíça. }\end{array}$ \\
\hline Booker Washington & Up from slavery & 1893 & Europa \\
\hline
\end{tabular}


Ser escrava, mulher e viajante:

\section{Harriet Jacobs e Amanda Berry Smith}

Linda Brent é a narradora de Incidents in the life of a slave girl. Written by herself, publicado originalmente em língua inglesa, no ano de 1861. Linda Brent é o alter ego de Harriet Ann Jacobs, nascida escrava, nos Estados Unidos, em 1813. Harriet nasceu e viveu, ao longo do século XIX. No prefácio escrito pela autora (assinado como Linda Brent), em 1861, a mesma destaca que optou por pseudônimos, o que não significa que sua obra seja ficção:

Leitor, podes ter certeza de que esta narrativa não é fictícia. Sei que algumas de minhas aventuras podem parecer inacreditáveis, mas apesar disso são rigorosamente verídicas. Não exagerei os males causados pela Escravidão; pelo contrário, minhas descrições ficam muito aquém dos fatos. Ocultei os nomes dos lugares e dei nomes fictícios às pessoas. Não tinha motivos para ser reservada em relação a mim mesma, mas julguei que seria um ato de bondade e consideração para com os outros adotar essa atitude. (JACOBS, 1988, p. 23)

A obra possui várias edições, publicadas em diferentes períodos. A edição utilizada no presente trabalho é a tradução em língua portuguesa, de 1988, publicada pela editora Campus, organizada e editada por Jean Fagan Yellin, que também escreve a introdução mais recente da obra. O livro apresenta-se estruturado com um prefácio de Harriet Jacobs, introdução de Lydia Maria Child ${ }^{5}$ e 41 capítulos. Apresenta, também, ilustrações e correspondência ativa e passiva de Harriet. Foi a partir das cartas de Harriet que a historiadora Jean Fagan Yellin evidenciou que, sim, se tratava da escrita em primeira pessoa de uma escrava, e não uma "falsa narrativa de escravo". A partir

5 Lydia Maria Child (1802-1880) foi uma escritora, editora, jornalista e abolicionista, nascida em Massachusetts, Estados Unidos. das cartas de Harriet Jacobs, é possivel concluir o papel desempenhado por Lydia Maria Child, revisora, e não autora da obra. Nas palavras da própria Child:

A seu pedido, revi o original, mas as modificações que fiz visaram mais aos meus objetivos de condensação e disposição lógica. Não acrescentei nada aos incidentes, nem modifiquei o conteúdo de suas observações muito pertinentes. Com insignificantes exceções, tanto as ideias como a linguagem são dela. Podei um pouco as excrescências, mas não tive, agora isso, razões para modificar a maneira viva e dramática de contar sua história. (CHILD apud JACOBS, 1988, p. 24)

A publicação do livro deu-se por conta da autora, que, após não ter conseguido um editor, decidiu fazê-lo através dos próprios meios. A autobiografia de Harriet Jacobs é considerada a principal escrita em primeira pessoa de uma mulher negra, elaborada antes da Guerra Civil, nos Estados Unidos.

Harriet Ann Jacobs viveu e morreu no século XIX (1813-1897). Nascida no cativeiro, na região da Carolina do Norte, fugiu para Nova York, em 1842, onde lutou pelo fim da escravidão nos Estados Unidos e fez uso da palavra para contar sua experiência, em sua autobiografia.

A experiência de Harriet Jacobs foi vastamente estudada nos Estados Unidos, sendo Jean Fagan Yellin uma referência importante. Jean Yellin escreveu trabalhos como Written by herself: Harriet Jacobs's slave narrative, artigo publicado na American Literature 53 (nov. 1981); e a biografia Harriet Jacobs: a life (2004). Organizou, ainda, a coletânea de documentos The Harriet Jacobs family papers (2008). $\mathrm{Na}$ introdução de Incidentes da vida de uma escrava, escrito por ela mesma, Jean Yellin afirma:

O feito de Harriet foi transformar-se em assunto literário com a, e através da, criação de sua narradora, Linda Brent. Essa narradora conta uma dupla história, dramatizando o triunfo dos seus 
esforços para evitar que seu senhor a estuprasse, para salvar dele os seus filhos, para esconder-se, para fugir e, finalmente, para conseguir a liberdade. E ao mesmo tempo, apresentando sua incapacidade de seguir os padrões sexuais em que acreditava. Solteira, ela estabelece uma ligação sexual, engravida, é condenada pela avó, e sofre culpa terrível. (YELLIN apud JACOBS, 1988, p. 3)

No Brasil, destaco os trabalhos de Abreu (2006) e Farias (2012), dissertações de mestrado defendidas na Universidade do Estado do Rio de Janeiro, que exploram diferentes aspectos das narrativas de mulheres escravizadas nos Estados Unidos.

Ainda na condição de escrava (pois a fuga para Nova York não a libertou imediatamente), Harriet Jacobs viajou como babá para a Inglaterra, em 1845, o que mereceu um capítulo de sua autobiografia: "Visita à Inglaterra":

Partimos de Nova Iorque e chegamos a Liverpol depois de uma agradável viagem de 12 dias. Seguimos diretamente para Londres e hospedamo-nos no Adelaide Hotel. O jantar pareceu-me menos opulento do que dos hotéis americanos, mas minha situação era indescritivelmente mais agradável. Pela primeira vez na vida, eu estava num lugar em que era tratada de acordo com meu comportamento, sem referência a minha cor. Sentia como se um grande peso me tivesse sido tirado do peito. Instalada num quarto agradável, com minha querida garotinha, descansei a cabeça no travesseiro, pela primeira vez, com a consciência deliciosa de uma liberdade pura, sem concessões. (JACOBS, 1988, p. 166)
Harriet Jacobs viveu quase um ano na Inglaterra, onde alega nunca ter sentido o preconceito em função da cor de sua pele, "na verdade, eu o esquecera totalmente, até que foi chegado o momento de voltarmos à América" (JACOBS, 1988, p. 167). A questão da educação mereceu destaque, no relato da escrava viajante:

Como eu cuidava constantemente da menina, tive pouca oportunidade de ver as maravilhas da grande cidade, mas observei a vida que fluía pelas suas ruas, e pareceu-me haver um estranho contraste com a estagnação de nossas cidades do sul. O Sr. Bruce levou a filha para passar dias com amigos em Oxford Crescent e decerto era necessário que eu a acompanhasse. Eu tinha ouvido falar do método sistemático de educação inglesa, e desejava muito que minha querida Mary se comportasse adequadamente. Observei com atenção seus companheiros de brincadeiras, e as respectivas amas, pronta a aprender qualquer lição na ciência da boa administração. As crianças eram mais rosadas do que as americanas, mas não notei qualquer diferença material, sob outros aspectos. Eram como todas as crianças - por vezes dóceis, por vezes rebeldes. (JABOCS, 1988, p. 166)

Nas palavras da própria autora, "a visita à Inglaterra foi um acontecimento memorável em minha vida" (JACOBS, 1988, p 167), todavia, o retorno aos Estados Unidos foi relatado como uma tediosa viagem de inverno e um triste sentimento, "o de ter medo do próprio país" (JACOBS, 1988, p. 168).

Tabela 2 - As viagens de Harriet Jacobs

\begin{tabular}{|c|c|l|}
\hline Destino & Data & \multicolumn{1}{c|}{ Motivo } \\
\hline Inglaterra & 1845 & $\begin{array}{l}\text { Harriet viaja para a Inglaterra com o viúvo } \\
\text { Nathaniel Parker Willis, como babá de Imogem. }\end{array}$ \\
\hline Boston e Inglaterra & 1858 & $\begin{array}{l}\text { Tentar editora e apoio para a publicação de sua } \\
\text { autobiografia. }\end{array}$ \\
\hline Filadélfia & 1861 & Vender o próprio livro. \\
\hline Inglaterra & 1868 & Obter recursos para um orfanato e asilo de idosos. \\
\hline
\end{tabular}

Fonte: Jacobs (1988). 
$\mathrm{Na}$ primeira viagem à Inglaterra, Harriet viajou na condição de escrava fugida. Já liberta, Harriet Jacobs realizou outras viagens à Inglaterra, com objetivos distintos. Na segunda viagem, procurava apoio para a publicação de sua autobiografia e, na terceira, tendo a filha como companheira de viagem, procurava obter recursos para um orfanato e asilo de idosos.

Outra mulher, nascida escrava e que teve na viagem um divisor de águas em sua existência, foi Amanda Berry Smith, autora da autobiografia intitulada An autobiography. The story of the Lord's dealings with Mrs. Amanda Smith, the colored evangelist, onde ela relata suas viagens pelos Estados Unidos da América, Inglaterra, Irlanda, Escócia, Índia e África. Amanda Berry Smith nasceu escrava, em 23 de janeiro de 1837, nos Estados Unidos. Após uma trajetória de percalços, tornou-se missionária. Durante 12 anos, Amanda Smith conheceu diferentes culturas e pessoas, e ainda visitou instituições diversas. $\mathrm{O}$ tom da narrativa muda, ganha feições de diário de viagem. Após viajar pelo mundo afora, escreveu uma autobiografia. Dos 36 capítulos que compõem o livro de Amanda Berry Smith, 17 exploram os tempos de viagem, o que evidencia a compreensão de que se tratou de um momento singular, um período percebido como excepcional, pois a autora dedica grande parte da narrativa aos tempos em que viajou pelo mundo, na condição de missionária. Conforme sinalizado por Ângela de Castro Gomes, fases específicas da vida, "como viagens, estadas de estudo e trabalho, experiências de confrontos militares, prisão", podem ser percebidas como períodos excepcionais em uma vida, e que levam, muitas vezes, às escritas de si (GOMES, 2004, p. 18).

Nos Estados Unidos, há alguns trabalhos sobre Amanda Smith. A pesquisadora e professora Adrienne Israel, da Guilford College, é autora do livro Amanda Berry Smith: from washerwoman to evangelist (1998). O trabalho é um estudo biográfico, no qual se exploram alguns aspectos da história de vida de Amanda Smith, que, de simples lavadeira, se tornou uma missionária que pregou e evangelizou em nível internacional. 0 estudo de Adrienne Israel confere grande destaque ao significado que a fé adquiriu na vida de Amanda, imprimindo destaque à filiação de Amanda Smith ao Woman's Christian Temperance Union e às ações desempenhadas por ela na Igreja Metodista.

Por sua vez, a dissertação de mestrado de autoria de Kimberly DeJoie Hill, defendida em 2008, na University of North Carolina, explora as relações raciais a partir de um conjunto de missionárias americanas. Para a autora, Amanda Smith "pregou uma mensagem espiritual de transformação, que incluiu a crítica ao preconceito racial" (HILL, 2008, p. 3), trabalhando entre os americanos brancos também. Assim, Kimberly DeJoie Hill defende que Amanda Berry Smith lutou por uma reconciliação racial, em uma era de segregação.

A tese de doutorado de Kelly Willis Mendiola (2002) também situa a trajetória de Amanda Smith, no conjunto de outras mulheres que atuaram no evangelismo das igrejas pentecostais, nos Estados Unidos. A autobiografia e os sermões de Smith são compreendidos como um testemunho da complexidade da identidade racial, chamando a atenção para a situação dos afro-americanos nos Estados Unidos da América.

Analisar autobiografias de missionárias do século XIX foi o foco do trabalho de Elizabeth Elkin Grammer (2003), que elegeu a experiência de Amanda Smith, dentre inúmeras evangélicas itinerantes. Outros estudos também exploram a relação autobiografias/missionárias evangélicas, dentre os quais DOUGLASSCHIN (2001); ANDREWS (1986b).

É perceptivel que tais estudos exploram, em grande medida, o lugar do Evangelho e o 
trabalho missionário na experiência de Amanda Smith, que não foi a única a percorrer o próprio país e o exterior, para difundir a palavra cristã.

Tabela 3 - As viagens de Amanda Berry

\begin{tabular}{|c|c|l|}
\hline Data & Viagem & \multicolumn{1}{|c|}{ Motivo } \\
\hline 1865 & Nova York & Estabelecer nova moradia. \\
\hline 1878 & Inglaterra & Conversão religiosa. \\
\hline 1879 & Índia & $\begin{array}{l}\text { Encontrar o missionário } \\
\text { metodista W. B. Osborn. }\end{array}$ \\
\hline 1882 & Libéria & Trabalho de caridade. \\
\hline 1890 & Estados Unidos & Retorno à terra natal. \\
\hline
\end{tabular}

Fonte: Smith (1893).

No exterior, Londres foi o primeiro destino da ex-escrava, que, de lavadeira, se tornou missionária evangélica. Após conhecer a Inglaterra e a Escócia, Amanda visitou Paris, além das cidades italianas de Roma, Florença e Nápoles. Conheceu também o Egito. Seguiu rumo à Índia, onde, entre muitas orações, visitou orfanatos. Assim, de conferência em conferência, visita após visita, Amanda Smith sentiu-se finalmente preparada para conhecer a África, seu grande desejo:

Eu acho que eu posso ver agora que Deus me queria na África, e Ele teve que me enviar para a Îndia para me educar um pouco antes que Ele poderia me dizer para ir para a África. Tenho certeza que se Ele tivesse me dito na Escócia que Ele queria que eu fosse para a África [...]. Mas, oh, como o Senhor é bom. Vou louvá-Lo sempre, e agradeço a Ele por tudo o grande privilégio de ver o que eu fiz no continente e no Egito. (SMITH, 1893, p. 286)

Diante da vastidão do continente africano, a missionária dos Estados Unidos demonstra encantamento com Alexandria, no Egito, onde lamenta não ter podido visitar a Escola Mahommedan, na qual cerca de 800 alunos estudavam o Alcorão. Segundo relataram para Amanda Smith, na referida escola, todos se sentavam em esteiras no chão (homens ou meninos), e balançavam-se para trás e para a frente. Estudavam em voz alta, para memorizar todo o Alcorão.

$\mathrm{Na}$ África, além de ter visitado a Monrovia, a Libéria e Serra Leoa, conheceu escolas e ajudou a fundar outras. Nos oito anos em que viveu no continente, denunciou as condições desiguais de acesso ao ensino, entre meninos e meninas, a ausência de materiais didáticos e livros, além do fato dos governos não demonstrarem muito interesse em abrir escolas, pois muitas das existentes eram fruto das ações de missionários religiosos de diferentes países:

As escolas missionárias têm feito o maior bem, eu acho. A Missão Presbiteriana, em Clay -Ashland, ao mesmo tempo é uma escola florescente. Eles tinham uma boa e grande casa de tijolos e anexos. Quando fui pela primeira vez à África, esses prédios estavam todos em bom estado, mas foram desocupados. A escola foi feita no lado oposto do rio. Sr. Albert King era o professor, e como sua casa estava do outro lado do rio, eu presumo que é por isso que a escola foi transferida para lá. (SMITH, 1893, p. 456)

A viagem representou a superação de muitos obstáculos nas vidas de Harriet Jacobs e Amanda Berry Smith. Ambas ampliaram os contatos e as redes de apoio, a partir do trânsito por outros países. A viagem alargou os horizontes de expectativas nas vidas destas duas mulheres nascidas na escravidão. 0 con- 
tato com diferentes culturas permitiu que tais mulheres fossem as senhoras de suas próprias vidas, autoras das próprias histórias.

\section{A viagem como fuga da escravidão: Frederick Douglass e John Brown}

O livro Slave life in Georgia: a narrative of the life, sufferings, and escape of John Brown, a fugitive slave, now in England ${ }^{6}$ foi editado por Louis Alexis Chamerovzow, ${ }^{7}$ na cidade de Londres, em 1855. Na capa do livro, consta a informação de que Chamerovzow era secretário da British and Foreign Anti-Slavery Society. Foi para este secretário que John Brown narrou as agruras dos tempos de escravidão nos Estados Unidos. Do relato oral, nasceu o livro, escrito a partir da escuta do outro. John Brown não recebeu instrução formal, sendo iletrado:

Eu não tenho instrução e até que eu me estabeleça, eu não necessito que me elevem. Mas eu tenho um tipo de experiência que eu acredito que poderia virar-me por conta própria. Eu sou aquilo o que chamam de companheiro útil. Eu sou um bom carpinteiro, e posso fazer qualquer maquinaria, me dê apenas as ferramentas. Eu entendo tudo sobre o crescimento do algodão, do tempo de preparação da terra para receber a semente até a lã e o empacotamento final [...]. Meu conhecimento não veio naturalmente até mim. Eu adquiri em uma escola muito árdua e eu quero que isso seja considerado. (BROWN, 1855$, p. 208) $)^{8}$

John Brown nasceu em 1810, na região de

6 Disponivel em: <http://docsouth.unc.edu/neh/ jbrown/jbrown.html>. Acesso em: 19 mai. 2014.

7 De acordo com o Oxford Dictionary of National Biography, Louis Alexis Chamerovzow (1816-1875) foi um ativista antiescravidão e autor, nascido em Brighton. Foi o editor do jornal British and Foreign Anti-Slavery Reporter. (Richard Huzzey, "Chamerovzow, Louis Alexis (1816-1875)", Oxford Dictionary of National Biography, Oxford University Press, May 2010). Disponivel em: <http://www.oxforddnb.com/view/article/101107>. Acesso em 23 jun. 2014.

8 Os trechos da documentação analisada neste trabalho são de livre tradução da autora.
Southampton County, na Virgínia. Quando escravo, chamava-se Fed. A narrativa, estruturada em 21 capítulos, inicia-se na infância, tempos dificeis para Brown, uma vez que precisava tomar conta das crianças menores, enquanto a mãe trabalhava nos campos. Ele recorda que, até os 12 anos, as crianças escravas costumavam andar nuas, ou, quando muito, usavam alguma camisa velha (BROWN, 1855, p. 4).

John Brown não nasceu com este nome. A longa travessia pela liberdade transformou este sujeito, que percorreu os Estados Unidos e o Canadá e encontrou na Inglaterra o caminho para a almejada liberdade.

Outro capítulo narrado com bastante dor por Jonh Brown foi a separação da mãe e a ida para o sul da Geórgia. Ali tornou-se adulto, trabalhando nas plantações de algodão, onde descreve ter sofrido muitas humilhações e maus-tratos (BROWN, 1855, p. 13). Na plantação de algodão, ficou amigo de John Glasgow, um escravo mais velho que havia sido um negro livre na marinha mercante inglesa e que mereceu um capítulo na autobiografia de Brown:

John Glasgow foi um nativo de Demerara, nascido de pais livres, dos quais herdou a condição de liberto. Quando muito criança, seu pai o levou para o mar, primeiro como um grumete [...]. Ele foi para a Inglaterra onde cresceu com muitas oportunidades, onde guardou algum dinheiro. (BROWN, 1855, p. 31)

A partir do contato com John Glasgow, Brown passou a revoltar-se ainda mais com o severo mestre. Passou, sistematicamente, a vislumbrar a Inglaterra como um destino, onde poderia viver livremente. Após inúmeras tentativas de fuga e vendas para quatro diferentes senhores, no ano de 1850, John Brown conseguiu chegar à Inglaterra.

Além da narrativa de Brown, a publicação Slave life in Georgia: a narrative of the life, sufferings, and escape of John Brown, a fugitive slave, now in England traz uma série de docu- 
mentos de autoridades e testemunhas inglesas, a respeito da presença de Brown na Inglaterra:

Nós, abaixo assinados certificamos nosso conhecimento de John Brown, que era um escravo nos Estados Unidos, no estado da Geórgia, e foi quatro vezes vendido. Ele veio para Lake Superior, para o refúgio, em 1847, e foi contratado por nossa Companhia. Ele foi contratado por nossa Companhia durante um ano e meio; durante esse tempo o encontramos tranquilo, honesto e trabalhador. Seu objetivo ao vir para a Inglaterra era ver o capitão Joseph Teague, por quem foi prometido apoio. Infelizmente, o capitão morreu na América, e J. Brown não tinha conhecimento de sua morte até que chegou a Redruth, em Cornwall, por isso significa que ele foi jogado para fora em um país estranho para e precisa de um pouco de apoio. Nós o ajudamos em tudo que estava ao nosso alcance. Nós o ouvimos várias vezes em palestras sobre Escravidão [...]. (BROWN, 1855, p. 242)

$\mathrm{Na}$ Inglaterra, Brown passou a viver como livre em Londres. Carpinteiro, casou-se com uma inglesa. Faleceu em 1876. Apesar de não ter recebido instrução formal, aprendeu diversos saberes, a partir da experiência e do trabalho. $O$ contato com pessoas como John Glasgow alimentou o desejo pela liberdade em Brown. Mesmo sem saber ler e escrever, compreendia a importância do registro escrito, tanto que narrou as próprias memórias para que fossem publicadas como livro, na luta contra a escravidão. Fugir para outro país foi o caminho para viver a liberdade.

Por sua vez, Frederick Douglass escreveu três autobiografias: Narrative of the life of Frederick Douglass, an american slave (1845); My bondage and my freedom (1855); Life and times of Frederick Douglass (1881). As duas primeiras autobiografias foram publicadas durante a vigência da escravidão nos Estados Unidos, ao passo que a terceira foi publicada no pós-abolição, também nos Estados Unidos. Nascido em 1818, no Condado de Talbot, "foi um escravo, um trabalhador livre em uma fundição, depois um orador em prol do movimento abolicionista, tanto nos EUA quanto no exterior, tendo viajando para a Inglaterra e a Irlanda" (DOUGLASS, 2016, p. 4).

Assim, o primeiro movimento de Frederick Douglass, no sentido de conquistar a liberdade foi a fuga, via mar. Percorreu muitos estados, até chegar a Nova York:

Minha vida livre começou no dia três de setembro de 1838. Na manhã do dia quatro, depois de uma jornada por demais nervosa e perigosa, mas tranquila, me encontrei na grande cidade de Nova York, um Homem Livre - um a mais na multidão que caminhava entre os muros imponentes da Broadway como as ondas confusas do mar bravio. (DOUGLASS, 2016, p. 183)

Depois da fuga e para não ser recapturado, os líderes do movimento abolicionista enviaram Frederick Douglass para a Inglaterra, retornando para os Estados Unidos, em 1846 (EMERSON, 2003, p. 9). A segunda viagem para o exterior ocorreu em 1859, quando Douglass realizou uma série de palestras contra a escravidão e pela luta por direitos (EMERSON, 2003, p. 9). Além de viajar para proteger-se e refugiar-se, Douglass fez uso da viagem para lutar contra a escravidão, por meio de palestras e discussões.

Além das três autobiografias, Frederick Douglass escreveu um manuscrito, um diário das viagens realizadas em 1886. Nesta viagem sentimental, Douglass visitou a Inglaterra, a França, a Itália, o Egito, a Grécia e a Suiça. Douglass sentiu a enorme diferença em relação às viagens que realizou, na condição de escravo, para a viagem na condição de homem livre:

Eu estou de novo no solo da querida velha Inglaterra. 0 contraste entre minha atual visita e aquela de 1845 é impressionante. Naquela eu vim como um escravo, agora eu venho como um homem livre. Naquela como um estranho, agora como um cidadão; naquela eu era jovem, agora, sou comparativamente mais velho; naquela eu defendia a causa dos meus irmãos, agora eu 
falo da liberdade deles e de seus progressos. (DOUGLASS, New York Times, 17 October 1886).

$\mathrm{Na}$ escrita de viagem na forma de diário, é importante considerar que as impressões e sensações da viagem são, também, seleções dos momentos de vida, o que passa ainda, pela seleção de certos acontecimentos significativos, estabelecendo entre eles conexões para thes dar coerência. Os diários podem ser analisados como escrita autorreferencial (ou escritas de si), "publicizados pelo historiador que os qualifica e os ressignifica como fonte/ documento ainda (CUNHA, 2007, p. 2). Além disso, conforme salienta Ângela de Castro Gomes, o significado do ato de escrever sobre a própria vida e a vida dos "outros ganha contornos específicos com a constituição do individualismo moderno" (GOMES, 2004b, p. 11), ressaltando a relação do indivíduo moderno com seus documentos.

A noção de "teatro da memória", em que a escrita é interpretada enquanto palco onde ocorre encenação dos múltiplos papéis sociais e das temporalidades, mesmo que esta não seja a intenção do sujeito em sua narrativa linear e coerente sobre si. A ideia de ilusão biográfica, conforme pontuada por Pierre Bourdieu (1996), auxilia na compreensão que o sujeito projeta sobre si para o outro, evidenciando a viagem enquanto "um grande feito" em sua vida, repleta de sacrificios.

Sem dúvida, cabe supor que o relato autobiográfico se baseia sempre, ou pelo menos em parte, na preocupação de dar sentido, de tornar razoável, de extrair uma lógica ao mesmo tempo retrospectiva e prospectiva, uma consistência e uma constância, estabelecendo relações inteligiveis, como a do efeito à causa eficiente ou final, entre os estados sucessivos, assim constituídos em etapas de um desenvolvimento necessário. (BOURDIEU, 1996, p. 184)

Um ponto de conexão entre as experiências de John Brown e Frederick Douglass foi a fuga e a Inglaterra como abrigo para a construção da liberdade. Ambos contaram com o apoio dos movimentos abolicionistas. A viagem representou a sobrevivência do sonho de liberdade para tais sujeitos em trânsito. Ambos enfrentaram o olhar suspeito e tiveram que usar de diferentes estratégias para não serem recapturados e levados novamente ao cativeiro.

\section{A viagem como consagração: Booker Washington}

Up from slavery: an autobiography ${ }^{9}$ (1901a) é o título de uma das três autobiografias escritas por Booker T. Washington. As outras intitulam-se: An autobiography. The story of my life and work (1901b) e My larger education: being chapters from my experience (1911). Inicialmente, a autobiografia de Booker Washington foi publicada na forma de artigos na revista Outlook e, devido ao sucesso junto ao público, foram publicados os dois livros em 1901. Mas por que ele publicou duas autobiografias, no mesmo ano? Segundo GLEDHILL (2014, p. 71), Up from slavery era dirigida a leitores brancos, enquanto An autobiography. The story of my life and work teria como público-alvo leitores negros. Up from slavery: an autobiography foi publicado pela Doubleday \& Company, de Nova York, enquanto An autobiography. The story of my life and work por J. L. NICHOLS \& COMPANY, Naperville, Illinois. O presente trabalho se concentrará no livro Up from slavery: an autobiography, seguindo uma indicação do próprio Booker Washington, que aconselhava a leitura de Up from slavery para aqueles que desejassem saber mais sobre o seu processo de escolarização (WASHINGTON, 1911, p. 10).

Booker T. Washington já foi explorado em muitos estudos acadêmicos nos Estados Unidos. No Brasil, a tese de Helen Sabrina Gledhill (2014) explora as trajetórias de Booker T.

9 Disponivel em: http://docsouth.unc.edu/fpn/washington/washing.html [Consulta em 20/01/2014]. 
Washington e Manuel Querino na luta contra as ideias racialistas. Para Gledhill, Booker T. Washington foi:

No Brasil, a história de Booker T. Washington (1856/1915) é ainda mais desconhecida que a de Querino, embora sua autobiografia romanceada Up From Slavery tenha sido enfoque de uma resenha detalhada publicada em várias edições do Diário da Bahia, em 1902. Depois, foi traduzida novamente por Graciliano Ramos com o título Memórias de um negro, lançado pela Editora Nacional em São Paulo em 1940. (GLEDHILL, 2014, p. 19)

"Um escravo entre escravos". Com essas palavras, Booker Washington inicia o capítulo um de sua autobiografia. Nascido escravo em uma fazenda de Franklin County, Virgínia, afirma não saber ao certo a data de seu nascimento. Acredita ter sido entre 1858 e 1859, perto de um posto dos Correios (WASHINGTON, 1901a, p. 1). Assim como Jonh Brown, Booker Washington descreve os tempos de cativeiro como terriveis, miseráveis, de total e completa desolação para os escravos. Logo menciona o fato que após a Guerra Civil foi declarado livre, portanto, viveu parte da infância como escravo. Se por um lado Booker menciona a mãe e o irmão, por outro, silencia sobre o pai, a respeito do qual diz nada saber (WASHINGTON, 1901a, p. 3). Acredita-se que o pai de Booker Washington fosse um homem branco desconhecido e, apesar de Booker Washington firmar-se sempre como negro, muitos na época o chamavam de "mulato" (GLEDHILL, 2014, p. 43).

No livro Memórias de um negro, autobiografia traduzida por Graciliano Ramos para a língua portuguesa, Booker Washington representa a viagem à Europa como um momento de vitória e consagração para um sujeito nascido na escravidão, pois: "o bem-estar e o luxo sempre me haviam parecido privilégio dos brancos. E de repente a Europa! O antigo escravo da Virgínia ia visitar Londres e Paris. Extraordinário! (WASHINGTON, 1940, p. 192).
Ainda no sentido de reforçar a superação dos tempos de escravidão, Booker Washington destaca a mudança no olhar em relação ao negro viajante, lembrando-se "das narrações dos pretos que não tinham tido bom acolhimento em navios americanos" (WASHINGTON, 1940, p. 193). O autor temia que pudesse sofrer algum tipo de afronta, "que não se realizou: a tripulação, de alto a baixo, e todos os viajantes, sem excetuar os sulistas, dispensaram-nos gentilezas" (WASHINGTON, 1940, p. 193). o tour de Booker Washington à Europa encaixa-se no que se convencionou denominar de Grand Tour, viagens por puro deleite e "amor à cultura" (SALGUEIRO, 2002).

Outro aspecto importante na viagem como legitimação, em Booker Washington, diz respeito ao sentido de ampliação da rede de sociabilidade do intelectual, nascido escravo e da atenção dada à consagração de outros negros no exterior:

Em Paris conhecemos o pintor negro Henry 0. Tanner e vimos com prazer que ele desfrutava reputação invejável nos meios artísticos e era respeitado em todas as classes da sociedade. Transmitindo a alguns amigos a intenção de ver no museu de Luxemburgo a tela dum preto americano, percebemos que nos ouviam com surpresa e dúvida. Só admitiam a existência do pintor depois que foram examinar o quadro. (WASHINGTON, 1940, p. 196)

Para Booker Washington, o negro precisa ser exemplo em todas as atividades, no sentido de provar, pelo mérito, que tem capacidades. Assim, "o exemplo do Sr. Tanner fortaleceu-me a convicção que não cesso de comunicar aos meus alunos. O negro subirá quando se tornar indispensável, quando fizer melhor que os outros as coisas que toda a gente faz" (WASHINGTON, 1940, p. 197).

Outra passagem interessante foi o retorno para os Estados Unidos. Neste momento, há uma conexão com um outro sujeito em trânsito, nascido na escravidão: Frederick Douglass: 
Após três meses de permanência na Europa, embarcamos em Southapton para o regresso, no S. Luis. Havia a bordo uma esplendida biblioteca oferecida pelos cidadãos de S. Luis, no Missouri. Entre os livros achei uma biografia de Frederick Douglass, obra curiosa, sobretudo na parte referente à viagem que o grande negro fez à Inglaterra. Não lhe permitiram entrar no salão: durante a travessia Douglass se conservou no convés. (WASHINGTON, 1940, p. 201)

Diferente de Frederick Douglass, o autor de Memórias de um negro não experimentou viajar na condição de escravo fugido. Todavia, Frederick Douglass também vivenciou a experiência do Grand Tour, conforme sinalizado por Mark Emerson (2003).

\section{Considerações finais}

Afinal, qual a importância de conhecer os escritos em primeira pessoa de sujeitos nascidos na escravidão nos Estados Unidos? Conforme sinalizado por Silva:

O conhecimento de trajetórias de ex-escravos é necessário no Brasil, país em que a memória é um direito negado à maior parte de sua população afrodescendente. Conhecer outras histórias é uma forma de olharmos para dentro e interrogarmos o processo de silenciamento e negação da nossa própria constituição e identidade. Estudar e conhecer trajetórias como as de Harriet Jacobs, Frederick Douglass e Booker Washington é um caminho essencial para uma História da Educação, no plural. (SILVA, 2016, p. 127)

\section{Referências}

ABREU, Aline. Celebrating womanhood and motherhood in (post)slave narratives: a contemporany reading of Harriet Jacobs's incidents in the life of a slave girl and Maya Angelous's I know why the bird sings. 246f, 2006. Dissertação (Mestrado em Literatura Inglesa) - Faculdade de Letras, Universidade do Estado do Rio de Janeiro, Rio de Janeiro, 2006.
A partir das autobiografias analisadas, é possivel aferir que a viagem não era privilégio dos sujeitos economicamente favorecidos; também não era privilégio masculino, pois mulheres como Amanda Berry e Harriet Jacobs viajaram. Todos os sujeitos do presente texto tiveram alguma passagem pela Inglaterra, o que se justifica pela língua inglesa, já que, além de facilitar a comunicação, também favorecia o fato da Inglaterra ser um reduto do abolicionismo no século XIX.

Entretanto, há diferenças nas viagens dos sujeitos nascidos na escravidão? Sim, há especificidades e aproximações nas experiências de tais pessoas.

John Brown fugiu para nunca mais voltar para a terra natal. Na Inglaterra, deixou de ser escravo fugido para ser trabalhador livre. Harriet Jacobs e Frederick Douglass também visitaram a Inglaterra na condição de escravos e, depois, na de libertos. Os sentidos das experiências de viagem nesses casos são distintos. Por sua vez, Amanda Berry Smith e Booker Washington não viajaram como escravos. A viagem para eles representou a ampliação de horizontes, o conhecimento de diferentes culturas e religiões.

Em comum, todos se tornaram escritores após a viagem. Todos escreveram, em primeira pessoa, sobre a importância das viagens em suas vidas, na luta pela construção da liberdade e da igualdade.

ANDREWS, William L. Tell a free story: the first century of afro-american autobiography, (1760-1865). Illinois: Illinois Press, 1986a. ok

ANDREWS, William L. Sisters of the spirit: three black women's autobiographies of the nineteenth century. Bloomington: Indiana University Press, 1986b.ok

BOURDIEU, Pierre. A ilusão biográfica. In: FERREIRA, 
Marieta de Moraes; AMADO, Janaina. (Orgs.). Usos \& abusos da história oral. 8. ed. Rio de Janeiro: FGV. 1996. p. 183-191.

BROWN, John. Slave life in Georgia: a narrative of the life, sufferings, and escape of John Brown, a fugitive slave, now in England. London: W. M. Wattz, 1855.

CUNHA, Maria Teresa S. Do baú ao arquivo: escritas de si, escritas do outro. Patrimônio e Memória, UNESP, v. 3, p. 45-62, 2007. [on-line]. Disponível em: <endereço eletrônico>. Acesso em: 20/01/2017

DOUGLASS, Frederick. A narrativa da vida de Frederick Douglass, um escravo americano: escrita por ele mesmo. Tradução de Leonardo Vidal. Boston: Createspace Independent Publishing Platform, 2016.

DOUGLASS, Frederick. Meus anos de cativeiro e liberdade. Gazeta da Tarde, 1883. Disponível em: <http:// hemerotecadigital.bn.br/ [Acesso em: 20/01/2017].

DOUGLASS-CHIN, Richard. Preacher woman sings the blues: the autobiographies of nineteenthcentury african american evangelists. Columbia, Missouri: University of Missouri Press, 2001. Ok, DOUGLASS-CHINEncyclopedia Britannica, disponível em: https://www.britannica.com/ [Acesso em: $20 / 01 / 2017\}$

EMERSON, Mark. Scholarly edition of the Grand Tour diaries of Frederick Douglass and Helen Pitts Douglass. 245f. Indianápolis: Master in Arts (Dissertation in History) Indiana University, 2003.

FARIAS, Adriana Merly. Female slave narratives consistency and permanence: a study of two texts from the XIXth and XXth centuries. $87 \mathrm{f}$. Dissertação (Mestrado em Literatura Inglesa) -Faculdade de Letras, Universidade do Estado do Rio de Janeiro, Rio de Janeiro, 2012.

GENOVESE, Eugene. Roll, Jordan, roll: the world the slaves made. New York: Vintage, 1972.

GLEDHILL, Helen Sabrina. Travessias racialistas no Atlântico negro: reflexões sobre Booker T. Washington e Manuel R. Querino. 302F. Salvador: Tese (Doutorado em Estudos Étnicos e Africanos), Universida- de Federal da Bahia, 2014.

GOMES, Ângela de Castro. Em família: a correspondência entre Oliveira Lima e Gilberto Freyre. In: GOMES, Ângela de Castro. (Org). Escrita de si, escrita da história. Rio de Janeiro: Editora FGV, 2004a. p. 51-76.

Escrita de si, escrita da história: a título de prólogo. In: GOMES, Ângela de Castro. (Org). Escrita de si, escrita da história. Rio de Janeiro: Editora FGV, 2004b. p. 7-24.

GRAMMER, Elizabeth Elkin. Some Wild Visions: Autobiographies by Female Itinerant Evangelists in Nineteenth Century America. New York: Oxford University Press, 2003, 211f.

HILL, Kimberly DeJoie. Careers across color lines: american women missionaries and race relations, 1870-1920. 242f. Chapel Hill: Tese (Doutorado em História), University of North Carolina, 2008

IANNI, Octávio. A metáfora da viagem. In: Enigmas da modernidade-mundo. Rio de Janeiro: Civilização Brasileira, 2000, cap. 1, p. 11-32.

ISRAEL, Adrienne. Amanda Berry Smith: from washerwoman to evangelist. Lanham, MA: Scarecrow Press, 1998.

JACOBS, Harriet. Incidentes na vida de uma escrava, contados por ela mesma. Rio de Janeiro: Campus, 1988.

LEITE, Miriam Moreira. Livros de viagem (18031900). Rio de Janeiro: Editora da UFRJ, 1997.

LEJEUNE, Philippe. 0 pacto autobiográfico. Belo Horizonte: Ed. UFMG, 2008.

MENDIOLA, Kelly Willis. The Hand of a Woman: Four Holiness-Pentecostal Evangelists and American Culture, 1840-1930. 498 f. Austin: Tese (Doutorado em Filosofia), University of Texas at Austin, 2002.

MILLER, Randall; SMITH, John. Dictionary of afro -american slavery. London: Westport: Greenwood Press, 1988.

North American Slave Narratives. Disponível em: <http://docsouth.unc.edu>. Acesso em: 01/03/2017]: OLNEY, J. I was born: slave narratives, their status as 
autobiography and as literature. In: DAVIS, Charles T.; GATES JR., Henry Louis. (Orgs.). The slave's narrative. New York: Oxford University Press, 1990. p. 148-175.

Oxford Dictionary of National Biography, Oxford University Press, May 2010. Disponivel em: <http:// oxforddnb.com>. [Acesso em 20/01/2017]

SALGUEIRO, Valéria. Grand Tour: uma contribuição à história do viajar por prazer e amor à cultura. Revista Brasileira de História, Viagens e viajantes, São Paulo, ANPUH, v. 22, n. 44, p. 289-310, 2002.

SILVA, Alexandra Lima da. Escritores da liberdade: autobiografias de escravos, memória e história da educação. Educação em foco, Belo Horizonte, v. 19, p. 103-132, 2016.

SMITH, Amanda Berry. An autobiography. The story of the Lord's dealings with Mrs. Amanda Smith the colored evangelist. Chicago: Meyer \& Brother Publishers, 1893.

The New York Times, 17/10/1886.

WASHINGTON, Booker T. The story of my life and work. Cincinnati, Ohio: W. H. Ferguson Company, 1901a.

Up from slavery: an autobiography. Garden City, NY: Doubleday \& Company Inc., 1901b.

My larger education: being chapters from my experience. Garden City, NY: Doubleday Page \& Company, 1911.

. Memórias de um negro. Traduzido por Graciliano Ramos. São Paulo: Companhia Editora Nacional, 1940 .

Recebido em: 09.03.2017

Aprovado em: 10.05.2017

Alexandra Lima da Silva é doutora em Educação pela Universidade do Estado do Rio de Janeiro (UERJ), com período de bolsa sanduíche financiado pela CAPES na Universidad de Alcalá e bolsa doutorado nota 10 da Fundação Carlos Chagas Filho de Amparo à Pesquisa do Estado do Rio de Janeiro (FAPERJ). Professora adjunta da Faculdade de Educação e do ProPed/UERJ da UERJ, Campus Maracanã. Pesquisadora da FAPERJ no programa Jovem Cientista do Nosso Estado (2015) e bolsista de produtividade UERJ/FAPERJ (Prociência 2017). e-mail: alexandralima1075@gmail.com

Alameda São Boaventura, n. 987, apt 310, bloco 1, Fonseca, Niterói, Rj - CEP: 24130-001.

Telefone: 2132546752 